\title{
TNF-a acutely enhances acid-sensing ion channel currents in rat dorsal root ganglion neurons via a p38 MAPK pathway
}

Wang-Ping Hu ( $\nabla$ wangping_hu@163.com )

Hubei University of Science and Technology https://orcid.org/0000-0003-1870-325X

\section{Shuang Wei}

Hubei University Of Science and Technology

Ying Jin

Hubei University Of Science and Technology

Ting-Ting Liu

Hubei University Of Science and Technology

Chun-Yu Qiu

Hubei University Of Science and Technology

\section{Research Article}

Keywords: tumor necrosis factor-a, acid-sensing ion channels, electrophysiology, nociceptive response, dorsal root ganglion neuron

Posted Date: February 26th, 2021

DOl: https://doi.org/10.21203/rs.3.rs-243161/v1

License: (c) (1) This work is licensed under a Creative Commons Attribution 4.0 International License. Read Full License

Version of Record: A version of this preprint was published at Journal of Neuroinflammation on April 14th, 2021. See the published version at https://doi.org/10.1186/s12974-021-02151-w. 


\section{Abstract}

Background Tumor necrosis factor-a (TNF-a) is a pro-inflammatory cytokine involved in pain processing and hypersensitivity. It regulates not only the expression of a variety of inflammatory mediators but also the functional activity of some ion channels. Acid-sensing ion channels (ASICs), as key sensors for extracellular protons, are expressed in nociceptive sensory neurons and contribute to pain signaling caused by tissue acidosis. It is still unclear whether TNF-a has an effect on functional activity of ASICs. Herein, we reported that a brief exposure of TNF-a acutely sensitized ASICs in rat dorsal root ganglion (DRG) neurons. Methods Electrophysiological experiments were performed on neurons from rat DRG. Nociceptive behaviour was induced by acetic acid in rats. Results A brief ( $5 \mathrm{~min})$ application of TNF-a rapidly enhanced ASIC-mediated currents in rat DRG neurons. TNF-a $(0.1-10 \mathrm{ng} / \mathrm{ml})$ dose-dependently increased the proton-evoked ASIC currents with an EC 50 value of $1.96 \pm 0.15 \mathrm{ng} / \mathrm{ml}$. TNF-a shifted the concentration-response curve of proton upwards with a maximal current response increase of $42.34 \pm$ $7.89 \%$. In current-clamp recording, an acute application of TNF-a also significantly increased acid-evoked firing in rat DRG neurons. The rapid enhancement of ASIC-mediated electrophysiological activity by TNFa was prevented by p38 mitogen-activated protein kinase (MAPK) inhibitor SB202190, but not by nonselective cyclooxygenase inhibitor indomethacin, suggesting that p38 MAPK is necessary for this enhancement. Behaviorally, TNF-a exacerbated acid-induced nociceptive behaviors in rats via activation of local p38 MAPK pathway. Conclusions These results suggest that TNF-a rapidly enhanced ASICmediated functional activity via a p38 MAPK pathway, which revealed a novel peripheral mechanism underlying TNF-a involvement in rapid hyperalgesia by sensitizing ASICs in primary sensory neurons.

\section{Introduction}

Tumor necrosis factor-a (TNF-a), a pro-inflammatory cytokine, plays a critical role in the development and maintenance of pain [1]. TNF-a is released by a variety of cells including inflammatory, immune, glia and neuronal cells [2,3]. And endogenous TNF-a levels increase under inflammatory and neuropathic pain conditions $[4,5]$. Neutralizing endogenous TNF-a with antibodies attenuates thermal and mechanical hyperalgesia in neuropathic pain [6,7]. Animals display higher sensitivity to thermal and mechanical stimuli after TNF-a is injected into the paw $[4,8,9]$. TNF-a regulates pain signaling through genomic and non-genomic mechanisms. On the one hand, TNF-a has long-lasting effects by regulating the expression of a variety of inflammatory mediators and modifying signaling proteins. On the other hand, TNF-a has also rapid onset effects by modulating the functional activity of a variety of ion channels. For example, TNF-a has been shown to acutely increase tetrodotoxin (TTX) -resistant sodium channel currents in dorsal root ganglion (DRG) neurons $[10,11]$. TNF-a also directly enhances the sensitivity of rat trigeminal neurons to capsaicin through a rapid non-genomic mechanism [12]. In addition, TNF-a regulates outward potassium channel currents, calcium channel currents and hyperpolarization-activated cation currents in other neurons [13-16]. Studies have shown that peripheral administration of TNF-a rapidly enhances ongoing activity in nociceptive fibers, resulting in acute mechanical and thermal hypersensitivity $[10,17$, 
18]. Acute modulation of these ion channels by TNF-a can account for the rapid onset of TNF-a-induced pain hypersensitivity [19].

Besides the above ion channels, acid-sensing ion channels (ASICs) are also expressed in both DRG cell bodies and sensory terminals, where they assemble as homomeric or heteromeric channels containing three ASIC subunits to sense changes in extracellular $\mathrm{pH}$ [20-22]. Among seven ASIC subunits, ASIC3 subunit is the most abundant in DRG and has emerged as a critical pH sensor [23]. Proton is a canonical ligand for ASICs. It is released and causes tissue acidosis under multiple pathological conditions such as inflammation, tissue injury, ischemic stroke and cancer [24-26]. Low pH (up to pH 6.0)-induced pain is significantly alleviated by non-selective ASIC inhibitor amiloride, suggesting that the pain sensation is mainly mediate by ASICs, but not by transient receptor potential vanilloid type 1 (TRPV1) [23, 27]. ASICs, especially ASIC3, are the major player in pain associated with tissue acidosis [23, 28-31].

In the present study, we investigated whether TNF-a had also a rapid effect on functional activity of ASICs in primary sensory neurons. We observed that a brief $(5 \mathrm{~min})$ application of TNF-a rapidly enhanced ASICmediated currents in rat DRG neurons via a p38 mitogen-activated protein kinase (MAPK)-dependent pathway. The present studies provided a novel explanation for the rapid sensitization of pain induced by TNF-a.

\section{Materials And Methods}

\section{Isolation of DRG neurons}

All experimental protocols were approved by the animal research ethics committee of Hubei University of Science and Technology. All procedures were made to minimize the sufferings of animals. SpragueDawley male rats (six- to seven-week old) were sacrificed. The DRGs were taken out and minced with fine spring scissors. The ganglion fragments were placed in a flask containing $5 \mathrm{ml}$ of Dulbecco's modified Eagle's medium (DMEM, Sigma). DMEM contained trypsin (type II-S, Sigma) $0.5 \mathrm{mg} / \mathrm{ml}$, collagenase (type I-A, Sigma) $1.0 \mathrm{mg} / \mathrm{ml}$ and DNase (type IV, Sigma) $0.1 \mathrm{mg} / \mathrm{ml}$, and was incubated at $35^{\circ} \mathrm{C}$ in a shaking water bath for 25-30 min. Soybean trypsin inhibitor (type II-S, Sigma) $1.25 \mathrm{mg} / \mathrm{ml}$ was then added to stop trypsin digestion.

\section{Electrophysiological recordings}

Whole-cell patch clamp and voltage-clamp recordings were carried out at room temperature $\left(22-25^{\circ} \mathrm{C}\right)$ using EPC-10 patch clamp amplifier and PULSE software (HEKA Electronic, Lambrecht, Germany). Dissociated neurons were placed into a 35-mm Petri dish and were bathed in an external solution containing (mM): $\mathrm{NaCl} 150, \mathrm{KCl} 5, \mathrm{CaCl}_{2} 2.5, \mathrm{MgCl}_{2} 2$, HEPES 10, d-glucose 10.Its pH was adjusted to7.4 with $\mathrm{NaOH}$ and its osmolarity to $330 \mathrm{mOsm} / \mathrm{L}$ with sucrose. Cells were kept for at least 60 min in normal external solution before the start of electrophysiological experiments. The neurons selected for electrophysiological experiment were $15-35 \mu \mathrm{m}$ in diameter, which are thought to be nociceptive neurons. Recording pipettes were pulled using a Sutter P-97 puller (Sutter Instruments, CA, USA). The micropipettes 
were filled with internal solution containing (mM): $\mathrm{KCl} 140, \mathrm{MgCl}_{2} 2, \operatorname{HEPES} 10$, EGTA 11, $\mathrm{Na}_{2} \mathrm{ATP} 4$, and $\mathrm{Na}_{2}$ GTP 0.3. Its $\mathrm{pH}$ was adjusted to 7.2 with $\mathrm{KOH}$ and its osmolarity to $310 \mathrm{mOsm} / \mathrm{L}$ with sucrose. The resistance of the recording pipette was in the range of $3-6 \mathrm{M} \Omega$. To establish a whole-cell configuration, a small patch of membrane underneath the tip of the pipette was aspirated to form a giga seal and then a negative pressure was applied to rupture it. The series resistance was compensated for by $70-80 \%$. The adjustment of capacitance compensation was also done before recording the membrane currents. The membrane voltage was maintained at $-60 \mathrm{mV}$ in all voltage-clamp experiments. Current-clamp recordings were obtained by switching to current-clamp mode after a stable whole-cell configuration was formed in voltage-clamp mode. Only cells with a stable resting membrane potential (more negative than $-50 \mathrm{mV}$ ) were used in the study.

\section{Drug application}

Drugs were obtained from Sigma Chemical Co. (St. Louis, MO, USA) and used in the experiments include: hydrochloric acid, TNF-a, SB202190, indomethacin, amiloride, APETx2, capsaicin, and AMG 9810. Different $\mathrm{pH}$ values were configured with hydrochloric acid and external solution. Working TNF-a and other drugs were freshly prepared in normal external solution and held in a series of independent reservoirs. The pipette tips connecting reservoirs were positioned $\sim 30 \mu \mathrm{m}$ away from the recorded neurons. The application of each drug was driven by gravity and controlled by the corresponding valve. To functionally characterize ASIC activity, we used AMG9810 (5 $\mu \mathrm{M})$ to block TRPV1 in the extracellular solution [32].

\section{Nociceptive behaviour induced by acetic acid in rats}

Rats were placed in a $30 \times 30 \times 30 \mathrm{~cm}$ Plexiglas chamber and allowed to habituate for at least $30 \mathrm{~min}$ before nociceptive behavior experiments. A double-blind experiment was carried out. Separate groups of rats were coded and pretreated with $50 \mu \mathrm{AMG} 9810(10 \mu \mathrm{M})$ together with vehicle, different doses of TNF-a, TNF-a + SB202190 in ipsilateral hindpaw before the injection of acetic acid. After 5 min, the other observers, who unaware of treatment allocation, subcutaneously administered acetic acid solution ( $1 \%$, $50 \mu \mathrm{l})$ into the hind paw using a 30 gauge needle connected to a $100 \mu \mathrm{L}$ Hamilton syringe. And nociceptive behavior (that is, number of flinches) was monitored for the next $5 \min [23,33]$. To demonstrate that TNF-a produced enhancement of acetic acid-induced behaviors through a local effect in the hindpaw, another group of rats received an injection of acetic acid in one hindpaw and TNF-a (10 ng in $50 \mu \mathrm{l}$ ) into contralateral hindpaw.

\section{Data analysis}

Data were statistically compared using the Student's t-test or one-way analysis of variance (ANOVA), followed by Bonferroni's post hoc test. Statistical analysis of concentration-response data was performed using nonlinear curve-fitting program ALLFIT. Data are expressed as mean \pm S.E.M.

\section{Results}




\section{TNF-a acutely enhanced ASIC-mediated currents in rat DRG neurons}

In the present study, AMG9810 $(5 \mu \mathrm{M})$ was added to external solution to block proton-induced TRPV1 activation. As shown in Fig.1A, a sudden drop in extracellular $\mathrm{pH}$ from 7.4 to 6.0 produced a rapid inward current $\left(\mathrm{I}_{\mathrm{pH} 6.0}\right)$ in DRG neurons. The $\mathrm{I}_{\mathrm{pH} 6.0}$ could be completely blocked by $10 \mu \mathrm{M}$ of amiloride, a broadspectrum ASIC channel blocker, and also by $2 \mu \mathrm{M}$ APETx2, an ASIC3 blocker. In contrast, capsaicin (100 $\mathrm{nM}$ ) failed to evoke any membrane currents in the presence of AMG9810. Thus, these acid-induced currents were considered to be ASIC currents or ASIC3-mediated currents after TRPV1 activation was blocked by AMG9810.

In some DRG neurons sensitive to acid stimuli, we first evaluated the effects of brief application of TNF-a on the ASIC currents. TNF-a was pre-incubated to DRG neurons for $5 \mathrm{~min}$ prior to application of $\mathrm{pH} 6.0$ acidic solution. As shown in Fig.1B and C, a brief ( $5 \mathrm{~min})$ application of TNF-a acutely increased the peak amplitude of $\mathrm{I}_{\mathrm{pH} 6.0}$. The enhancement of $\mathrm{I}_{\mathrm{pH} 6.0}$ occurred $5 \mathrm{~min}$ after the onset of TNF-a application. This enhancement of $\mathrm{I}_{\mathrm{pH} 6.0}$ was dependent upon the doses of TNF-a treatment. In a representative DRG neuron, the peak amplitude of $\mathrm{I}_{\mathrm{pH} 6.0}$ progressively increased as doses of pre-treated TNF-a increased from $0.3 \mathrm{ng} / \mathrm{ml}$ to $30 \mathrm{ng} / \mathrm{ml}$ (Fig.1B). Fig.1C showed the dose-response curve for TNF-a with an $\mathrm{EC}_{50}$ (halfmaximal effective dose) value of $1.96 \pm 0.15 \mathrm{ng} / \mathrm{ml}$. The results indicated that TNF-a rapidly enhanced ASIC currents in rat DRG neurons in dose-dependent manner.

We then investigated the effects of TNF-a on concentration-response curve for protons. ASIC currents were measured by applying a range of different $\mathrm{pH}$ acidifications in the absence and presence of TNF-a.

Fig.2A showed that peak amplitudes of $\mathrm{I}_{\mathrm{pH} 6.5}, \mathrm{I}_{\mathrm{pH} 5.5}$ and $\mathrm{I}_{\mathrm{pH} 4.5}$ increased after pre-application of $10 \mathrm{ng} / \mathrm{ml}$ TNF-a for 5 min. Fig.2B showed concentration-response curve for protons shifted upwards by TNF-a treatment. First, TNF- $a$ caused an increase of $42.34 \pm 7.89 \%$ in the maximal current response to $\mathrm{pH} 4.5$. Second, the Hill coefficient or slope of two curves had not significant difference in the absence and presence of TNF- $a(\mathrm{pH}: \mathrm{n}=1.30 \pm 0.19 ;$ TNF- $\mathrm{a}+\mathrm{pH}: \mathrm{n}=1.32 \pm 0.21 ; \mathrm{P}>0.1$, post hoc Bonferroni's test). Third, the $\mathrm{pH}_{0.5}$ ( $\mathrm{pH}$ for half-maximal activation) values of two curves had also no statistical difference ( $\mathrm{pH}: \mathrm{pH}_{0.5}=5.94 \pm 0.12 ;$ TNF- $\mathrm{a}+\mathrm{pH}: \mathrm{pH}_{0.5}=6.03 \pm 0.16 ; \mathrm{P}>0.1$, post hoc Bonferroni's test). We therefore concluded that sensitization of ASICs by TNF-a was not due to a change in the apparent affinity of ASICs for protons.

\section{TNF-a-induced enhancement of ASIC currents was mediated by p38 MAPK, but not cyclooxygenase}

We further explored the pathway linking TNF-a to its effect on ASIC currents. It has been demonstrated that TNF-a can signal through activation of p38 MAPK in DRG neurons as well as many other cell types $[10,34,35]$. In addition, TNF-a can induce functional expression of cyclooxygenase (COX)-2 in cultured DRG neurons [36]. We therefore investigated the roles of p38 MAPK and COX in the enhancement of ASIC currents by TNF-a. As shown in Fig. $3 A$ and $B$, the amplitude of $I_{\mathrm{pH} 6.0}$ increased $44.14 \pm 4.26 \%$ by TNF-a $(10 \mathrm{ng} / \mathrm{ml})$ pre-treatment alone. SB202190, a fast-acting p38 MAPK inhibitor, was applied to DRG neurons for 3 min followed by mixture of SB202190 and TNF-a for additional 5 min. The pretreatment of 
SB202190 $(10 \mu \mathrm{M})$ substantially prevented the TNF-a-mediated increase in ASIC currents, and the amplitude of $\mathrm{I}_{\mathrm{pH} 6.0}$ increased only $2.67 \pm 3.71 \%$ ( $\mathrm{P}<0.01$, compared with TNF-a pretreatment alone, oneway ANOVA followed by post hoc Bonferroni's test, $n=6$; Fig.3A and B). Indomethacin, a potent inhibitor for both COX-1 and COX-2, was also applied to DRG neurons similar to SB202190 treatment. In contrast, indomethacin failed to change TNF-a-mediated increase in ASIC currents (Fig.3A and B). In addition, SB202190 or indomethacin alone had no effect on $\mathrm{I}_{\mathrm{pH} 6.0}$ (data not shown). These results indicated that p38 MAPK, but not COX, is necessary for TNF-a-induced enhancement of ASIC currents.

\section{TNF-a increased acid-evoked action potentials in rat DRG neurons}

ASICs are non-selective cation channels, once activation by acidification, which leads to membrane potential depolarization and neuronal excitation. We further observed whether TNF-a had effects on acidevoked action potentials of rat DRG neurons. Although proton-induced TRPV1 activation was blocked in the presence of $5 \mu \mathrm{M}$ AMG9810, we observed that an acid stimulus of $\mathrm{pH} 6.0$ induced not only a rapid inward current with voltage-clamp recording, but also bursts of action potentials (APs) under currentclamp condition in the same DRG neuron (Fig.4A and C). Consistent with that observed under voltageclamp conditions, TNF-a pre-treatment also acutely increased the number of APs evoked by acidic stimuli of pH 6.0 in DRG neurons (Fig.4A and B). In six DRG neurons treated with TNF-a (10 ng/ml for $5 \mathrm{~min}$ ), the number of APs evoked by acidic stimuli of $\mathrm{pH} 6.0$ significantly increased $(\mathrm{P}<0.01$, paired $t$-test, $\mathrm{n}=6$, Fig.4B). In other six DRG neurons pre-treated with SB202190 (10 $\mu \mathrm{M})$, TNF-a failed to increase the number of APs ( $P \otimes 0.1$, paired $t$-test; $n=6, F i g .4 C$ and $D)$. These results indicated that TNF- $a$ also rapidly enhanced acid-evoked APs via a p38 MAPK-dependent pathway.

\section{TNF-a exacerbated acid-induced nociceptive behaviors in rats}

Our above electrophysiological studies showed that TNF-a acutely sensitized ASICs via activation of p38 MAPK in vitro. We further ascertained whether TNF-a had effects on ASIC-mediated nociceptive behaviors through interacting with ASICs in vivo. Our previous studies observe that intraplantar injection of acetic acid into rats elicits ASIC-mediated nociceptive behaviors even if AMG $9810(10 \mu \mathrm{M})$ blocked the

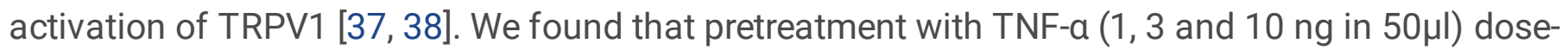
dependently exacerbated the acid-induced nociceptive behaviors $(p<0.05$ and 0.01 , one-way ANOVA followed by post hoc Bonferroni's test, $n=10$; Fig.5). However, the aggravating effect of TNF-a on acidinduced nociceptive behaviors was prevented in rats, which were co-treated with the p38 MAPK inhibitor

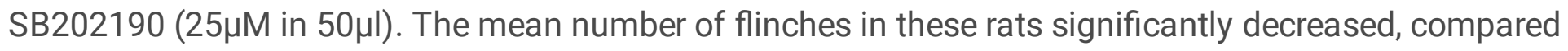
with that observed in rats pretreated with TNF-a $(10 \mathrm{ng}$ in $50 \mu \mathrm{l})$ alone $(\mathrm{p}<0.01$, one-way ANOVA followed by post hoc Bonferroni's test, $n=10 ;$ Fig.5). In addition, injection of TNF-a (10 ng in 50 $\mu$ l) into the contralateral paws did not change acid-induced nociceptive behaviors. These results indicated that TNF-a exacerbated acid-induced nociceptive behaviors in rats via activation of local p38 MAPK pathway.

\section{Discussion}


This study examined the effects of a brief exposure of TNF-a on functional activity of ASICs. We demonstrated that acute application of TNF-a rapidly enhanced ASIC-mediated and acid-evoked currents and action potentials in dissociated rat DRG neurons through a p38 MAPK-dependent mechanism. Behaviorally, TNF-a also exacerbated acid-induced nociceptive responses in rats via activation of local p38 MAPK pathway.

After proton-induced TRPV1 activation was block by AMG9810, capsaicin failed to induce any membrane currents. Thus, the low pH-evoked currents maybe mediated by only ASICs in the present study. The conclusion was confirmed by the results that these currents were completely blocked by ASIC channel blocker amiloride and ASIC3 blocker APETx2. It has been found that there are seven ASIC subunits in DRG neurons, of which ASIC3 subunit is the most abundant [23]. We therefore considered that these low $\mathrm{pH}$ evoked currents may be ASIC or ASIC3-like currents, although precise ASIC subunits need to be identified.

The present study showed that TNF-a can rapidly sensitized ASICs. A brief (5min) exposure of TNF-a dose-dependently enhanced ASIC currents in rat DRG neurons. TNF-a shifted upwards concentrationresponse curve for protons with a significant increase in the maximal current response to protons, whereas apparent affinity of ASICs for proton did not change. A brief exposure of TNF-a also rapidly increased the number of action potentials evoked by low $\mathrm{pH}$ in current-clamp experiments. Obviously, the two results corroborated each other. Together, TNF-a can rapidly exert an enhancing effect on the electrophysiological activity of ASICs in rat DRG neurons. This is consistent with earlier results showing that an application of TNF-a has an acute influence on ion channel currents including TTX-resistant $\mathrm{Na}^{+}$ currents, L-type $\mathrm{Ca}^{2+}$ currents, and TRPV1 currents $[10,12,19]$.

TNF-a exerts its biological effects by associating with two tumor necrosis factor receptors: TNFR-1 and TNFR-2, which are expressed in DRG neurons [39-42]. TNFR-1 is shown to be involved in the enhancement of TTX-resistant $\mathrm{Na}^{+}$currents [10]. TNFR1 activates multiple signaling pathways including ceramide signaling and activation of several MAPK pathways [34, 35]. It has been shown that TNF-a acutely regulates TTX-resistant $\mathrm{Na}^{+}$channel currents and hyperpolarization-activated cation currents via a p38 MAPK pathway $[10,15,16]$. The present data showed that p38 MAPK may underlie the acute sensitization of ASICs by TNF-a, since administration of a p38 MAPK inhibitor SB202190 prevented the TNF-a-induced enhancement not only in ASIC-mediated electrophysiological activity in vivo but also in acid-induced nociceptive behaviors in vitro. While acute exposure (5min) of TNF-a enhanced ASIC currents, the effects were likely to result from a posttranslational modification of ASICs by TNF-a, such as phosphorylation. It has been shown that activation of p38 MAPK increases TTX-resistant sodium channel currents by phosphorylation of L1 loop serines of Nav1.8 channels [43]. Future work should examine whether ASICs can be phosphorylated by p38 MAPK.

It has been shown that TNF-a leads to COX-2-dependent production of prostaglandin E2 [44, 45]. prostaglandin E2 increases Nav1.8 current density in a protein kinase A (PKA) and protein kinase C (PKC) dependent manner $[46,47]$. Application (for $15 \mathrm{~min}$ ) of TNF-a suppresses sustained potassium current in rat sensory neurons, via stimulating the synthesis and release of endogenous prostaglandins [48]. Our 
recent study also shows that prostaglandin E2 potentiates ASIC currents via intracellular PKC and PKA signaling pathways [37]. However, the COX-2-dependent mechanisms are expected to have a relatively slow onset. For example, TNF-a enhances the sensitivity of sensory neurons to capsaicin via a COX-2dependent pathway, which requires about 4 hours to become effective [49]. In addition, acute TNF-amediated rapid onset hypersensitivity is COX independent [11]. We found that enhancement of ASIC currents by TNF-a was not blocked by indomethacin, a potent non-selective COX inhibitor. Thus, the COXdependent mechanisms may not well explain the rapid effects of TNF-a on ASIC function. In addition, it has been reported that TNF-a trimers insert into the cell membrane to form a sodium-permeable ion channel under conditions of low pH $(\sim \mathrm{pH}=5-6)[50,51]$. But we did not observed that TNF-a evoked any membrane currents in DRG neurons. Thus we believed the rapid effects of TNF-a on ASIC function were mediated by its cognate receptors, but not by TNF-a ion channels.

Under inflammatory and neuropathic pain conditions, various mediators are released, such as ATP, prostanoids, protons, and TNF-a. They contribute to peripheral sensitization in terminals of nociceptor neurons [52]. Clinically, levels of TNF-a have been shown to elevate in several pain conditions [53]. Endogenous TNF- $a$ and its receptors are up-regulated in several models of pain [4, 5, 39]. Peripheral inflammation also results in p38 MAPK activation in nociceptive DRG neurons, which participates in inflammatory hyperalgesia [54]. Protons are released from damaged cells and the de-granulation of mast cells during inflammation, resulting in local acidification. These released protons are enough to activate ASICs [55]. Once both TNF- $a$ and protons are locally released together at some sites, they could initiate and/or sensitize nociceptive process through activating their cognate receptors embedded in membrane of peripheral nerve terminals of nociceptive sensory neurons. Herein, we showed that the released TNF-a could rapidly enhanced ASIC-mediated and proton-activated currents in the same DRG neurons via a p38 MAPK pathway. In this work, we used cell bodies of DRG neurons as a simple and accessible model to examine the characteristics of the membrane of peripheral terminals. The sensitization of ASICs receptors by TNF-a may also occur in peripheral terminals. Behaviorally, we observed that TNF-a augmented acid-induced nociceptive responses in rats via activation of local p38 MAPK pathway. The TNF-a-induced rapid enhancement in ASIC-mediated electrophysiological activity could underlie exacerbation of nociceptive responses to acidification by TNF-a.

\section{Conclusion}

In summary, our results indicated that acute application of TNF-a rapidly enhanced ASIC-mediated electrophysiological activity and acidosis-evoked pain, which revealed a novel peripheral mechanism underlying rapid sensitization to nociceptive stimuli by peripheral administration of TNF-a. ASICs represent downstream targets of TNF-a and therapy targeting ASICs is likely useful for treating inflammatory and neuropathic pain.

\section{Declarations}

\section{Acknowledgement}


Not applicable.

\section{Funding}

This work was supported by the National Natural Science Foundation of China (No. 81671101).

\section{Availability of data and materials}

Not applicable.

\section{Author contributions}

WPH, SW and YJ conceived and designed the study, SW, YJ, TTL and CYQ, performed experiments. SW and $\mathrm{YJ}$ analysed the data. WPH, SW and YJ wrote the manuscript. All authors have read and approved the final manuscript.

\section{Statement of conflicts of interest}

We have no conflict-of-interest to declare.

\section{Ethics approval and consent to participate}

The experimental protocol was approved by the animal research ethics committee of Hubei University of Science and Technology (No. 2020-07).

\section{Consent for publication}

Not applicable.

\section{Abbreviations}

ANOVA, one-way analysis of variance; APs, action potentials; ASICs, acid-sensing ion channels; COX, cyclooxygenase; DMEM, Dulbecco's modified Eagle's medium; DRG, dorsal root ganglion; $\mathrm{EC}_{50}$, halfmaximal response; $\mathrm{I}_{\mathrm{pH}}$, proton-gated current; $\mathrm{MAPK}$, mitogen-activated protein kinase; PKA, protein kinase A; PKC, protein kinase C; TNF-a, tumor necrosis factor-a; TNFR, tumor necrosis factor receptor; TRPV1, transient receptor potential vanilloid type 1 ; TTX, tetrodotoxin;

\section{References}

1. Junger $\mathrm{H}$, Sorkin LS: Nociceptive and inflammatory effects of subcutaneous TNFalpha.Pain 2000, 85:145-151.

2. Wagner R, Myers RR: Endoneurial injection of TNF-alpha produces neuropathic pain behaviors. Neuroreport 1996, 7:2897-2901. 
3. Dubovy P, Jancalek R, Klusakova I, Svizenska I, Pejchalova K: Intra- and extraneuronal changes of immunofluorescence staining for TNF-alpha and TNFR1 in the dorsal root ganglia of rat peripheral neuropathic pain models.Cell Mol Neurobio/ 2006, 26:1205-1217.

4. Woolf CJ, Allchorne A, Safieh-Garabedian B, Poole S: Cytokines, nerve growth factor and inflammatory hyperalgesia: the contribution of tumour necrosis factor alpha. Br J Pharmaco/ 1997, 121:417-424.

5. Schafers M, Geis C, Svensson Cl, Luo ZD, Sommer C: Selective increase of tumour necrosis factoralpha in injured and spared myelinated primary afferents after chronic constrictive injury of rat sciatic nerve.Eur J Neurosci 2003, 17:791-804.

6. Lindenlaub T, Teuteberg P, Hartung T, Sommer C: Effects of neutralizing antibodies to TNF-alpha on pain-related behavior and nerve regeneration in mice with chronic constriction injury.Brain Res 2000, 866:15-22.

7. Sommer C, Lindenlaub T, Teuteberg P, Schafers M, Hartung T, Toyka KV: Anti-TNF-neutralizing antibodies reduce pain-related behavior in two different mouse models of painful mononeuropathy.Brain Res 2001, 913:86-89.

8. Cunha FQ, Poole S, Lorenzetti BB, Ferreira SH: The pivotal role of tumour necrosis factor alpha in the development of inflammatory hyperalgesia.Br J Pharmacol 1992, 107:660-664.

9. Wacnik PW, Eikmeier LJ, Simone DA, Wilcox GL, Beitz AJ: Nociceptive characteristics of tumor necrosis factor-alpha in naive and tumor-bearing mice.Neuroscience 2005, 132:479-491.

10. Jin X, Gereau RWt: Acute p38-mediated modulation of tetrodotoxin-resistant sodium channels in mouse sensory neurons by tumor necrosis factor-alpha.J Neurosci 2006, 26:246-255.

11. Gudes S, Barkai O, Caspi Y, Katz B, Lev S, Binshtok AM: The role of slow and persistent TTX-resistant sodium currents in acute tumor necrosis factor-alpha-mediated increase in nociceptors excitability. $J$ Neurophysio/ 2015, 113:601-619.

12. Khan AA, Diogenes A, Jeske NA, Henry MA, Akopian A, Hargreaves KM: Tumor necrosis factor alpha enhances the sensitivity of rat trigeminal neurons to capsaicin.Neuroscience 2008, 155:503-509.

13. Diem R, Meyer R, Weishaupt JH, Bahr M: Reduction of potassium currents and phosphatidylinositol 3-kinase-dependent AKT phosphorylation by tumor necrosis factor-(alpha) rescues axotomized retinal ganglion cells from retrograde cell death in vivo.J Neurosci 2001, 21:2058-2066.

14. Soliven B, Albert J: Tumor necrosis factor modulates Ca2+ currents in cultured sympathetic neurons.J Neurosci 1992, 12:2665-2671.

15. Zhang $H$, Dougherty PM: Acute inhibition of signalling phenotype of spinal GABAergic neurons by tumour necrosis factor-alpha.J Physiol 2011, 589:4511-4526.

16. Zhang H, Nei H, Dougherty PM: A p38 mitogen-activated protein kinase-dependent mechanism of disinhibition in spinal synaptic transmission induced by tumor necrosis factor-alpha.J Neurosci 2010, 30:12844-12855.

17. Sorkin LS, Xiao WH, Wagner R, Myers RR: Tumour necrosis factor-alpha induces ectopic activity in nociceptive primary afferent fibres.Neuroscience 1997, 81:255-262. 
18. Sorkin LS, Doom CM: Epineurial application of TNF elicits an acute mechanical hyperalgesia in the awake rat.J Peripher Nerv Syst 2000, 5:96-100.

19. Czeschik JC, Hagenacker T, Schafers M, Busselberg D: TNF-alpha differentially modulates ion channels of nociceptive neurons.Neurosci Lett 2008, 434:293-298.

20. Alvarez de la Rosa D, Zhang P, Shao D, White F, Canessa CM: Functional implications of the localization and activity of acid-sensitive channels in rat peripheral nervous system.Proc Nat/ Acad Sci U S A 2002, 99:2326-2331.

21. Benson CJ, Xie J, Wemmie JA, Price MP, Henss JM, Welsh MJ, Snyder PM: Heteromultimers of DEG/ENaC subunits form H+-gated channels in mouse sensory neurons.Proc Natl Acad Sci U SA 2002, 99:2338-2343.

22. Deval E, Lingueglia E: Acid-Sensing lon Channels and nociception in the peripheral and central nervous systems. Neuropharmacology 2015, 94:49-57.

23. Deval E, Noel J, Lay N, Alloui A, Diochot S, Friend V, Jodar M, Lazdunski M, Lingueglia E: ASIC3, a sensor of acidic and primary inflammatory pain.EMBO J 2008, 27:3047-3055.

24. Deval E, Noel J, Gasull X, Delaunay A, Alloui A, Friend V, Eschalier A, Lazdunski M, Lingueglia E: Acidsensing ion channels in postoperative pain.J Neurosci 2011, 31:6059-6066.

25. Wemmie JA, Taugher RJ, Kreple CJ: Acid-sensing ion channels in pain and disease.Nat Rev Neurosci 2013, 14:461-471.

26. Kweon HJ, Suh BC: Acid-sensing ion channels (ASICs): therapeutic targets for neurological diseases and their regulation. BMB Rep 2013, 46:295-304.

27. Ugawa S, Ueda T, Ishida Y, Nishigaki M, Shibata Y, Shimada S: Amiloride-blockable acid-sensing ion channels are leading acid sensors expressed in human nociceptors.J Clin Invest 2002, 110:11851190.

28. Dulai JS, Smith ESJ, Rahman T: Acid-sensing ion channel 3: An analgesic target.Channels (Austin) 2021, 15:94-127.

29. Mogil JS, Breese NM, Witty MF, Ritchie J, Rainville ML, Ase A, Abbadi N, Stucky CL, Seguela P: Transgenic expression of a dominant-negative ASIC3 subunit leads to increased sensitivity to mechanical and inflammatory stimuli.J Neurosci 2005, 25:9893-9901.

30. Karczewski J, Spencer RH, Garsky VM, Liang A, Leitl MD, Cato MJ, Cook SP, Kane S, Urban MO: Reversal of acid-induced and inflammatory pain by the selective ASIC3 inhibitor, APETx2.Br J Pharmacol 2010, 161:950-960.

31. Mamet J, Baron A, Lazdunski M, Voilley N: Proinflammatory mediators, stimulators of sensory neuron excitability via the expression of acid-sensing ion channels.J Neurosci 2002, 22:1066210670 .

32. Gavva NR, Tamir R, Qu Y, Klionsky L, Zhang TJ, Immke D, Wang J, Zhu D, Vanderah TW, Porreca F, et al: AMG 9810 [(E)-3-(4-t-butylphenyl)-N-(2,3-dihydrobenzo[b][1,4] dioxin-6-yl)acrylamide], a novel vanilloid receptor 1 (TRPV1) antagonist with antihyperalgesic properties.J Pharmacol Exp Ther 2005, 313:474-484. 
33. Omori M, Yokoyama M, Matsuoka Y, Kobayashi H, Mizobuchi S, Itano Y, Morita K, Ichikawa H: Effects of selective spinal nerve ligation on acetic acid-induced nociceptive responses and ASIC3 immunoreactivity in the rat dorsal root ganglion.Brain Res 2008, 1219:26-31.

34. Wu H: Assembly of post-receptor signaling complexes for the tumor necrosis factor receptor superfamily.Adv Protein Chem 2004, 68:225-279.

35. Pollock J, McFarlane SM, Connell MC, Zehavi U, Vandenabeele P, MacEwan DJ, Scott RH: TNF-alpha receptors simultaneously activate $\mathrm{Ca}+$ mobilisation and stress kinases in cultured sensory neurones. Neuropharmacology 2002, 42:93-106.

36. Fehrenbacher JC, Burkey TH, Nicol GD, Vasko MR: Tumor necrosis factor alpha and interleukin-1beta stimulate the expression of cyclooxygenase II but do not alter prostaglandin E2 receptor mRNA levels in cultured dorsal root ganglia cells. Pain 2005, 113:113-122.

37. Zhou YM, Wu L, Wei S, Jin Y, Liu TT, Qiu CY, Hu WP: Enhancement of acid-sensing ion channel activity by prostaglandin E2 in rat dorsal root ganglion neurons.Brain Res 2019, 1724:146442.

38. Qiu F, Qiu CY, Liu YQ, Wu D, Li JD, Hu WP: Potentiation of acid-sensing ion channel activity by the activation of 5-HT(2) receptors in rat dorsal root ganglion neurons.Neuropharmacology 2012, 63:494-500.

39. Shubayev VI, Myers RR: Axonal transport of TNF-alpha in painful neuropathy: distribution of ligand tracer and TNF receptors.J Neuroimmunol 2001, 114:48-56.

40. Schafers M, Sorkin LS, Geis C, Shubayev VI: Spinal nerve ligation induces transient upregulation of tumor necrosis factor receptors 1 and 2 in injured and adjacent uninjured dorsal root ganglia in the rat.Neurosci Lett 2003, 347:179-182.

41. Vandenabeele P, Declercq W, Beyaert R, Fiers W: Two tumour necrosis factor receptors: structure and function. Trends Cell Biol 1995, 5:392-399.

42. Leo M, Argalski S, Schafers M, Hagenacker T: Modulation of Voltage-Gated Sodium Channels by Activation of Tumor Necrosis Factor Receptor- 1 and Receptor-2 in Small DRG Neurons of Rats.Mediators Inflamm 2015, 2015:124942.

43. Hudmon A, Choi JS, Tyrrell L, Black JA, Rush AM, Waxman SG, Dib-Hajj SD: Phosphorylation of sodium channel $\mathrm{Na}(\mathrm{v}) 1.8$ by $\mathrm{p} 38$ mitogen-activated protein kinase increases current density in dorsal root ganglion neurons.J Neurosci 2008, 28:3190-3201.

44. Maier JA, Hla T, Maciag T: Cyclooxygenase is an immediate early gene induced by interleukin-1 in human endothelial cells.J Biol Chem 1990, 265:10805-10808.

45. Mark KS, Trickler WJ, Miller DW: Tumor necrosis factor-alpha induces cyclooxygenase-2 expression and prostaglandin release in brain microvessel endothelial cells.J Pharmacol Exp Ther 2001, 297:1051-1058.

46. England S, Bevan S, Docherty RJ: PGE2 modulates the tetrodotoxin-resistant sodium current in neonatal rat dorsal root ganglion neurones via the cyclic AMP-protein kinase A cascade.J Physiol 1996, 495 ( Pt 2):429-440. 
47. Gold MS, Levine JD, Correa AM: Modulation of TTX-R INa by PKC and PKA and their role in PGE2induced sensitization of rat sensory neurons in vitro.J Neurosci 1998, 18:10345-10355.

48. Liu BG, Dobretsov M, Stimers JR, Zhang JM: Tumor Necrosis Factor-alpha Suppresses Activation of Sustained Potassium Currents in Rat Small Diameter Sensory Neurons.Open Pain J 2008, 1:1.

49. Nicol GD, Lopshire JC, Pafford CM: Tumor necrosis factor enhances the capsaicin sensitivity of rat sensory neurons.J Neurosci 1997, 17:975-982.

50. Kagan BL, Baldwin RL, Munoz D, Wisnieski BJ: Formation of ion-permeable channels by tumor necrosis factor-alpha.Science 1992, 255:1427-1430.

51. Baldwin RL, Stolowitz ML, Hood L, Wisnieski BJ: Structural changes of tumor necrosis factor alpha associated with membrane insertion and channel formation.Proc Natl Acad Sci U S A 1996, 93:10211026.

52. Woolf CJ, Ma Q: Nociceptors-noxious stimulus detectors.Neuron 2007, 55:353-364.

53. Fernandes JC, Martel-Pelletier J, Pelletier JP: The role of cytokines in osteoarthritis pathophysiology.Biorheology 2002, 39:237-246.

54. Ji RR, Samad TA, Jin SX, Schmoll R, Woolf CJ: p38 MAPK activation by NGF in primary sensory neurons after inflammation increases TRPV1 levels and maintains heat hyperalgesia.Neuron 2002, 36:57-68.

55. Reeh PW, Steen KH: Tissue acidosis in nociception and pain.Prog Brain Res 1996, 113:143-151.

\section{Figures}



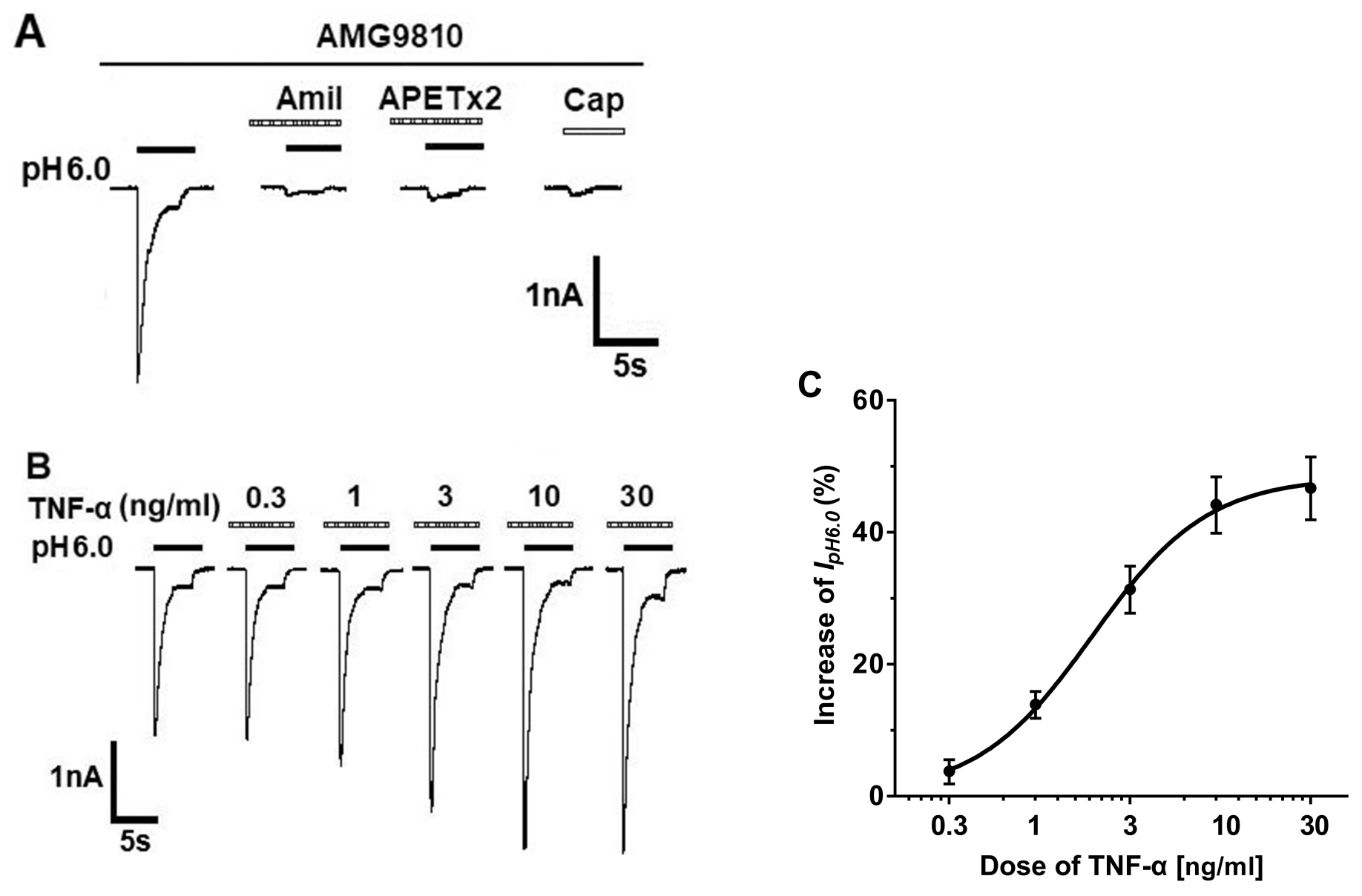

Wei et al. Fig.1

\section{Figure 1}

TNF-a acutely enhanced ASIC-mediated currents in rat DRG neurons A. Representative current traces were evoked by application of a pH 6.0 acidic solution for $5 \mathrm{~s}$ in a tested DRG neuron in the presence of AMG9810 $(5 \mu \mathrm{M})$. The low pH-induced current (IpH6.0) could be blocked by broad-spectrum ASIC channel blocker amiloride (Amil, $10 \mu \mathrm{M})$ and ASIC3 blocker APETx2 $(2 \mu \mathrm{M})$. Capsaicin (Cap, $100 \mathrm{nM})$ failed to evoke any membrane currents in the presence of AMG9810 (5 $\mu \mathrm{M})$. All membrane potentials were clamped at $-60 \mathrm{mV}$. B. The sequential current traces illustrated that the amplitude of IpH6.0 progressively increased after different doses of TNF-a was pre-treated to a representative DRG cell. C. The graph showed TNF-a dose-dependently increased IpH6.0 with an EC50 of $1.96 \pm 0.15 \mathrm{ng} / \mathrm{ml}$. Each point represents the mean \pm SEM of 7-10 cells. 

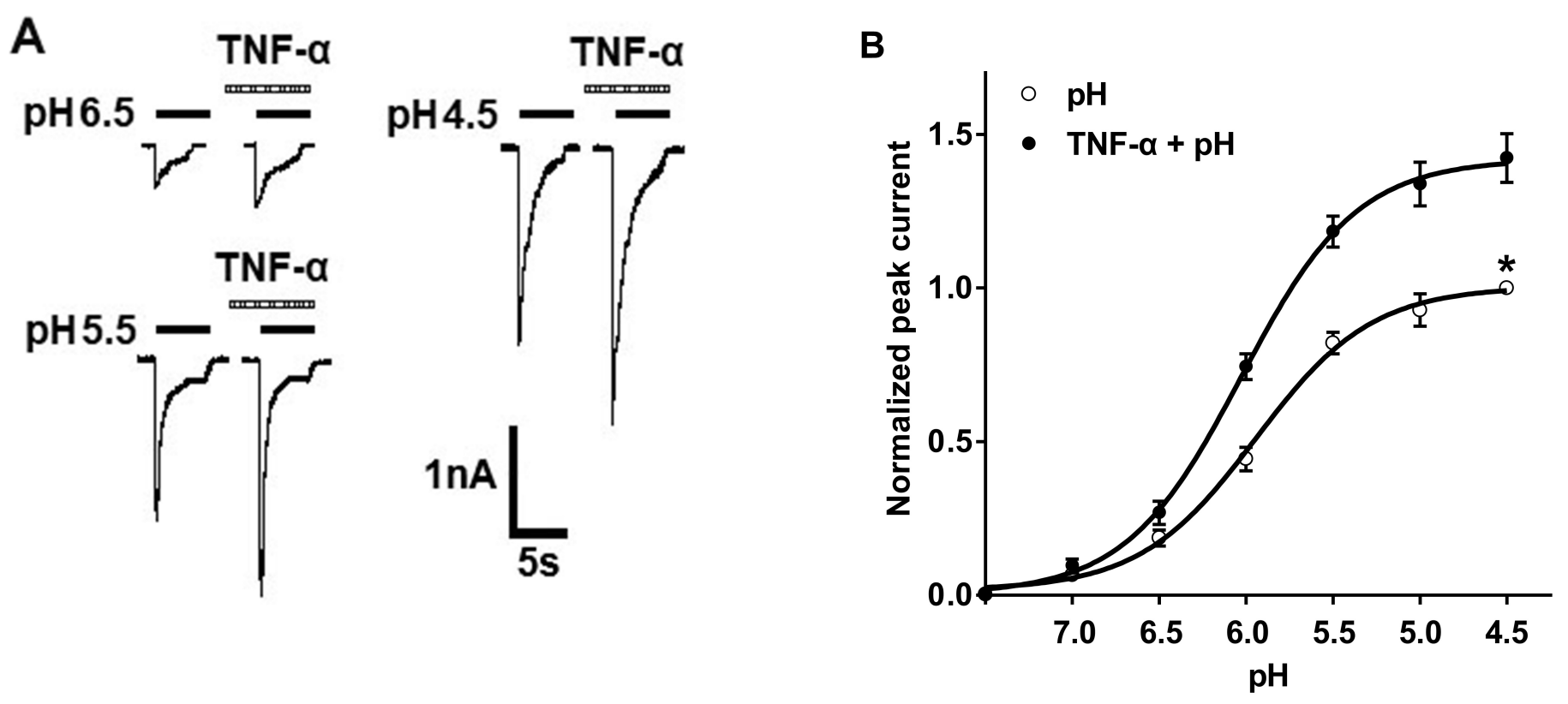

Wei et al. Fig.2

Figure 2

TNF-a shifted upwards the concentration-response curve for protons A. Sequential currents were evoked by three different low pH values in the absence and presence of $10 \mathrm{ng} / \mathrm{ml}$ TNF-a pretreatment. B.

Concentration-response curves for protons in the absence $(\mathbf{O})$ and presence $(\mathbf{0})$ of TNF-a. Concentrationresponse curve for protons shifted upwards in the presence of extracellular TNF-a $(10 \mathrm{ng} / \mathrm{ml})$. Each point represents the mean \pm S.E.M. of 7-10 neurons. All peak current values were normalized to the peak current maximally activated by $\mathrm{pH} 4.5$ applied alone in the absence of TNF-a (marked with asterisk). The figure shows averaged data fitted with the Hill equation. 


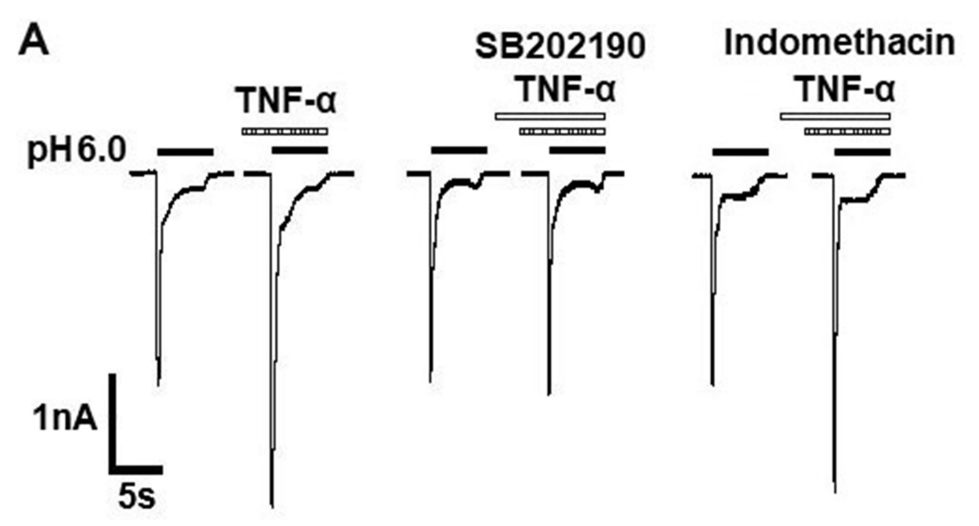

B

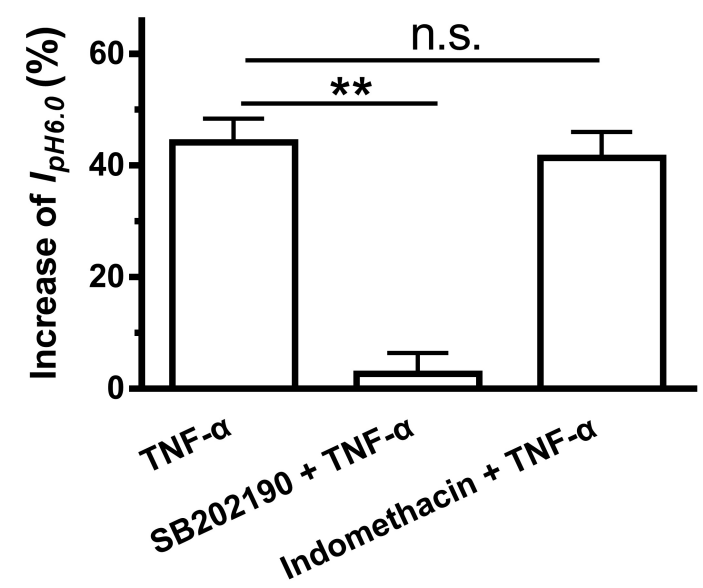

Wei et al. Fig.3

Figure 3

p38 MAPK, but not COX, was required for TNF-a-induced enhancement of ASIC currents. Representative current traces in (A) and the bar graph in (B) showed that the effects of TNF- $a(10 \mathrm{ng} / \mathrm{ml})$ alone, $p 38$ MAPK inhibitor SB202190 plus TNF- $a$, and non-selective COX inhibitor indomethacin plus TNF- $a$ on $\mathrm{pH}$ 6.0 acid-induced currents. IpH6.0 was enhanced by TNF-a $(10 \mathrm{ng} / \mathrm{ml})$ pre-applied alone for $5 \mathrm{~min}$, and the TNF-a $(10 \mathrm{ng} / \mathrm{ml})$ enhancement of IpH6.0 was blocked by the pre-treatment of SB202190 $(10 \mu \mathrm{M}, 3+5=8$ $\mathrm{min})$, but not by the pre-treatment of indomethacin $(30 \mu \mathrm{M}, 3+5=8 \mathrm{~min})$. Statistical tests were performed using one-way ANOVA followed by post hoc Bonferroni's test, and significance is shown $* \star P<0.01$. n.s. Not significant. $n=6$ in each column. 

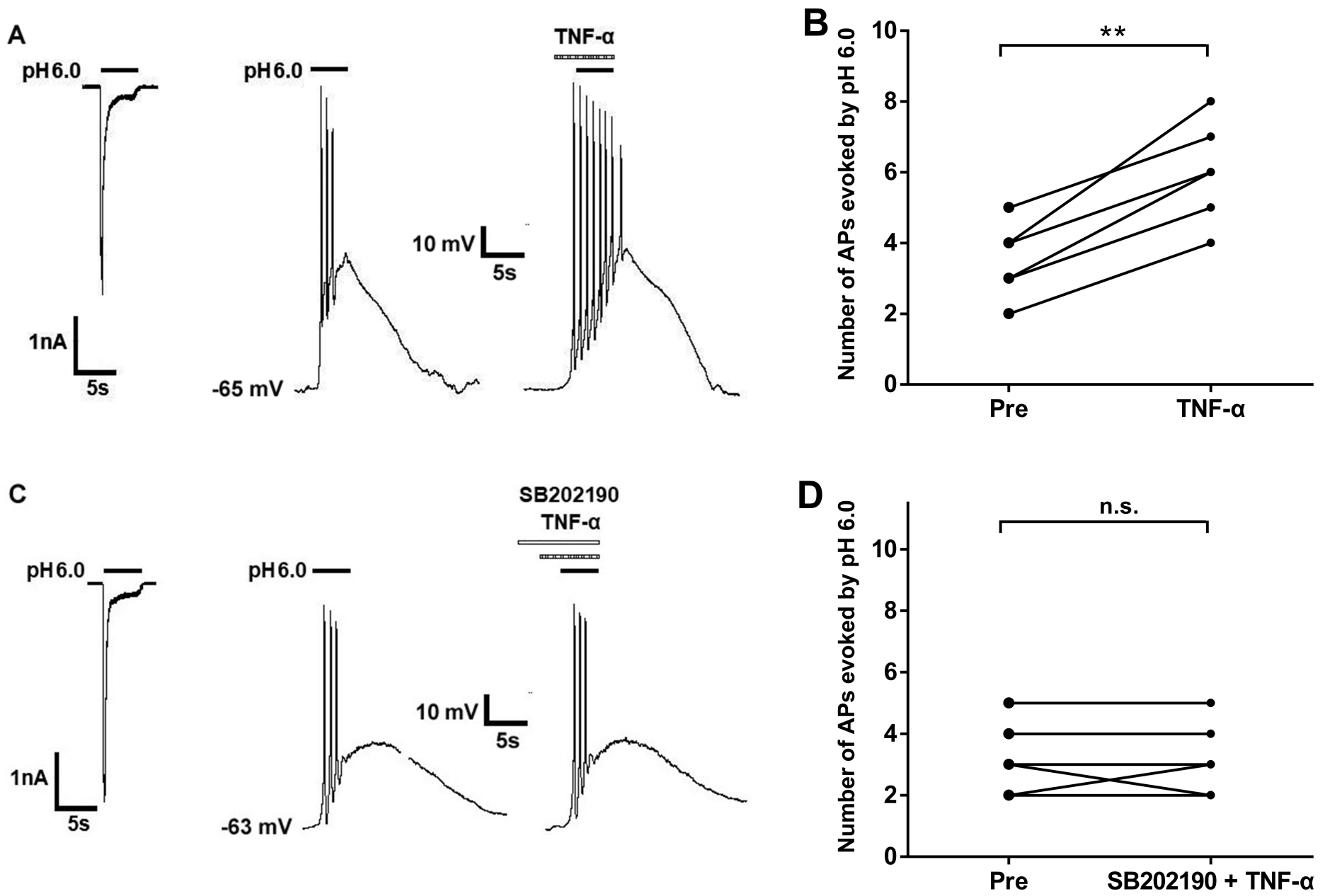

Wei et al. Fig.4

\section{Figure 4}

TNF-a increased acid-evoked action potentials in rat DRG neurons $A$ and $C$. In the same DRG neuron, a pH 6.0 acidic stimulus induced not only a rapid inward current with voltage-clamp recording, but also action potential burst under current-clamp condition. Original action potentials (APs) were recorded before and after application of TNF-a (10 ng/ml, $5 \mathrm{~min})$ alone (A) or co-application of both TNF-a $(10 \mathrm{ng} / \mathrm{ml}, 5 \mathrm{~min})$

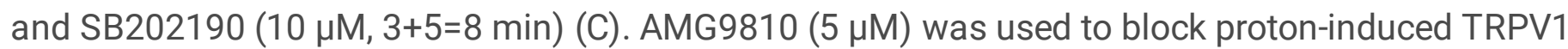
activation. $B$ and $D$. The graphs showed the number of acid-evoked APs increased by pre-application of TNF-a alone, but not by co-application of both TNF-a and SB202190. ${ }^{*} P<0.01$, paired t-test, $n=6$ cells. 


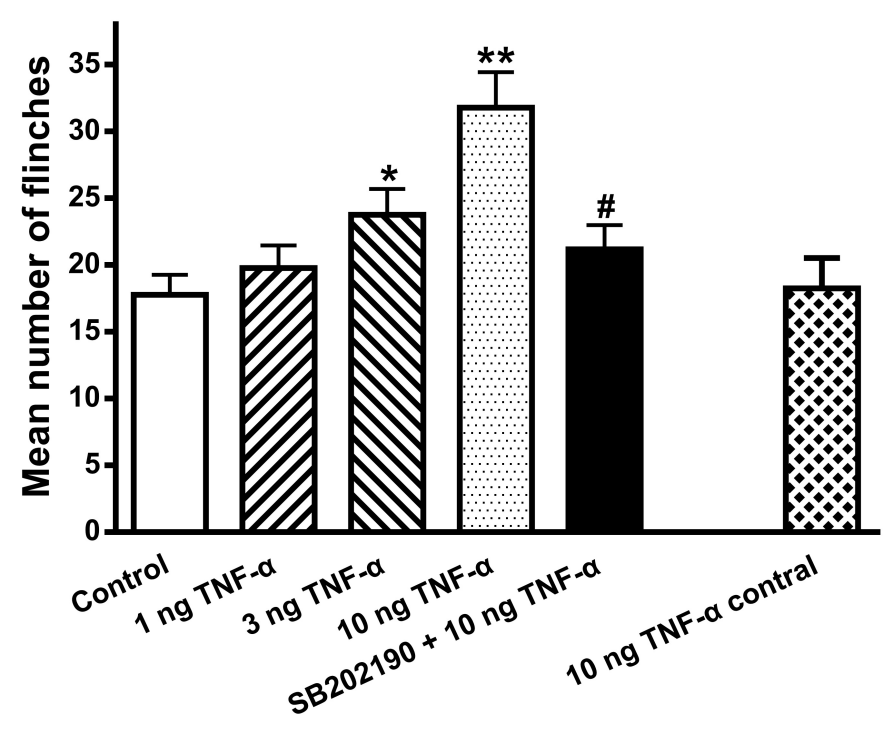

Wei et al. Fig.5

Figure 5

TNF- $a$ exacerbated acid-induced nociceptive behaviors in rats Nociceptive responses were evoked by intraplantar injection of acetic acid $(1 \%, 50 \mu \mathrm{l})$ in rats in the presence of the TRPV1 inhibitor AMG9810 $(10 \mu \mathrm{M})$. Intraplantar pretreatment of TNF-a (1, 3 and $10 \mathrm{ng})$ dose-dependently increased the number of acid-induced flinching. TNF-a (10 ng) exacerbating effect on nociceptive behaviors was reversed by intraplantar co-treatment of p38 MAPK inhibitor SB202190 (25 $\mu \mathrm{M})$. Rats (10 ng TNF-a contral group) injected with acetic acid into one hind paw and TNF-a (10 ng) into the contralateral hind paw displayed similar nociceptive behaviors to those seen in control rats. Each bar represents the number of flinches that animals spent licking/lifting the injected paw during first 5-min observation period. ${ }^{*} \mathrm{P}<0.05$, ${ }^{*} \mathrm{P}<$ 0.01 , one-way ANOVA followed by post hoc Bonferroni's test, compared with control column; $\# P<0.05$, one-way ANOVA followed by post hoc Bonferroni's test, compared with $10 \mathrm{ng}$ TNF-a column. Each group represents the mean \pm S.E.M. of 10 rats. 